\title{
A comparative study of emotional intelligence in offenders with antisocial personality disorder and normal population at a tertiary care centre in Hyderabad, Telangana
}

\author{
Shruti Agnihotri ${ }^{*}$, Anitha Rayirala ${ }^{2}$ \\ ${ }^{1}$ Postgraduate, ${ }^{2}$ Associate Professor, Dept. of Psychiatry, Institute of Mental Health, Hyderabad, Telangana, India
}

Best paper award “Dr. P. R Reddy - IMH Alumni association P.G award" at TSPSYCON, Mahabubnagar and Hyderabad, held on 6 September 2020.

\section{*Corresponding Author: Shruti Agnihotri}

Email: shrutiagnihotri1993.sa@gmail.com

\begin{abstract}
Background: Emotional intelligence refers to ability to monitor own and other people's emotions. Lack of emotional intelligence can lead to many disturbances in one's life. A comparison of emotional intelligence in offenders with antisocial personality disorder and in normal population has been done in this study.

Aim: The aim is to study emotional intelligence in offenders with antisocial personality disorder and compare it with normal population at a tertiary care centre in Hyderabad.

Methodology: It is a cross-sectional and comparative study done at Institute of mental health, Hyderabad. Study sample includes 70 males, out of this 35 were offenders diagnosed with antisocial personality disorder and remaining 35 were from normal population. Tools used in this study are semi-structured intake pro-forma for sociodemographic details and criminal history, Goldberg's 12 item General health questionnaire, Mangal emotional intelligence inventory, International classification of diseases-10 criteria.

Results: The offenders group with antisocial personality disorder scored less on emotional intelligence test domains such as intrapersonal awareness, interpersonal awareness, intrapersonal management, interpersonal management and the total emotional intelligence score when compared to normal individuals and the difference between the two groups was found to be statistically significant. $(\mathrm{p}=0.000)$

Conclusion: The offenders with antisocial personality had significantly lower Emotional intelligence in comparison to the normal group and an inverse relation was observed between levels of emotional intelligence and number of crimes committed.
\end{abstract}

Keywords: Emotional intelligence, Antisocial personality disorder, Criminal offenses.

\section{Introduction}

The term "emotional intelligence" was first used in 1964 in a paper by Michael Beldoch and in 1966 by B. Leuner in his paper 'Emotional intelligence and emancipation'. However, emotional intelligence was fully known and given importance with the publication of Goleman's book: Emotional intelligence - Why it can matter more than IQ.

Emotional intelligence is defined as "the ability to monitor one's own and other people's emotions, to discriminate between different emotions and label them appropriately and to use emotional information to guide thinking and behaviour". 1

The individuals with higher emotional intelligence are less likely to succumb to the negative impacts of stressors, while effectively help individuals deal with negative emotions and promote more positive emotions in its place. Deficits in emotional intelligence might lead to a number of adjustment issues. A person who cannot regulate his/her emotions well or understand the emotions of others may have difficulty in social situations. The individual may also have difficulty planning an emotionally fulfilling lifestyle.

Emotional intelligence is related to hostility and criminality. ${ }^{2-5}$ Individuals with low emotional intelligence are more prone for risky behaviour and are less empathetic. ${ }^{6}$ They cannot regulate their own emotions which will result in inappropriate behaviour and it is difficult to maintain high morals. $^{7}$

Antisocial personality disorder has a deeply ingrained and rigid dysfunctional thought process that focuses on callous unconcern for the feelings of others and persistent attitude of irresponsibility and disregard for social norms, rules and obligations. They are not capable of maintaining enduring relationship though having no difficulty in establishing them. Antisocial personality disorder individuals tend to have low tolerance to frustration and a low threshold for discharge of aggression. They don't express any guilt for their actions and lack empathy for others. There is proneness to blame others and offer plausible rationalisations for their behaviour which has brought them in conflict with society.

Emotional intelligence is based on an individuals abilities to tackle with their emotions and other's emotions as well which is lacking in antisocial personality leading to more personal and interpersonal conflicts. According to Meloy, an individual who qualifies for a diagnosis of antisocial personality disorder most likely lacks the ability to experience emotions such as pleasure, gratitude, empathy, sympathy, remorse or any feelings that enables him/her to connect with others emotionally. ${ }^{8}$

Study done by Goleman on emotional intelligence was based on four domains i.e., (a) self-awareness - is awareness of one's own emotional state, recognising how one's behaviour will impact others and paying attention to know how others can influence one's own emotional state, (b) self-management involves getting along well with others, handling conflict effectively and using sensitivity to another person's feelings to manage interactions effectively, (c) social awareness is about caring what others are going 
through and understanding about others in social networks, (d) relationship management includes the ability to get along well with others, make bonds and also managing conflict. Therefore emotional intelligence allows individuals to persist in situations in which they encounter barriers to success. ${ }^{9}, 10$

Another study done by Harrod et al, in 2005 on adolescents for assessing emotional intelligence along with demographic characteristics like age, sex, household income etc. had showed significant difference of emotional intelligence score between males, females and also education of the individuals affected the emotional intelligence score. Emotional intelligence can be conceptualized as a person's "success-oriented traits." 11

There are vast number of studies conducted on emotional intelligence of medical students, postgraduates and results showed that medical students, both men and women, had good level of emotional intelligence and it decreased with increase in total workload $(\mathrm{p}=0.013)$, having night duty hours and having emergency duty among the postgraduate students respectively. ${ }^{12,13}$ Studies conducted on emotional intelligence in nurses and the results suggested that Emotional Intelligence is a useful tool for nurse leaders and contributes decisively to the achievement of effective management in healthcare. ${ }^{14}$

A study was done to assess the relationship between emotional intelligence and criminal behaviour has stated that offenders had low emotional intelligence and also it varied with the type of crime i.e., murderers had lowest emotional intelligence followed by drug dealers and thieves. ${ }^{15}$ This link was also supported by other studies which were conducted in juvenile detainees. ${ }^{16}$ There are in fact many studies done on evaluating emotional intelligence in criminals and all those studies have consistently shown that there are deficits in the emotional intelligence in criminals. ${ }^{17-20}$ The relationships between trait psychopathy callousness, empathy, emotional intelligence, criminal thinking, and illegal behaviours was studied in a sample of male college students which revealed that participants who were more involved in criminal activities scored high on trait psychopathy and had low emotional intelligence. ${ }^{21}$

A study of relationship between emotional intelligence an criminal behaviour among convicted criminals when compared to normal subjects showed that criminals had lower emotional intelligence. ${ }^{22}$

There are various studies done on individuals with antisocial personality disorder world-wide to assess emotional intelligence. But same results cannot be generalised to Indian population as there will be a difference in the level of education, cultural aspects and also family background of the individuals. Which makes it important to consider these factors and understand how it can effect emotional intelligence of an individual in the Indian context.

However, there are no Indian studies which have assessed emotional intelligence in antisocial personality disorder and compared it with normal population. Hence the need for present study.

\section{Aim}

The aim is to study emotional intelligence in offenders with antisocial personality disorder and compare it with normal population at a tertiary care centre in Hyderabad.

\section{Objectives}

1. To assess emotional intelligence in individuals with antisocial personality disorder.

2. To assess emotional intelligence in normal individuals.

3. To compare emotional intelligence of offenders with antisocial personality disorder with normal individuals.

\section{Materials and Methods}

The study was conducted on a total of 70 individuals. Out of which 35 patients were offenders of various crimes admitted in forensic ward of Institute of mental health, Hyderabad and rest 35 individuals from the community were selected after age and gender matching was done. Study was conducted after ethics committee approval was obtained from Osmania medical college ethics committee.

\section{Study design}

Cross sectional and comparative study.

1. Study duration: 3 months. (Jan - March 2020)

2. Study done at: Forensic ward, Institute of mental health, Hyderabad and individuals from community.

\section{Study subjects}

1. Subjects diagnosed with Dissocial / Antisocial personality disorder as per International classification of diseases-10 criteria.

2. Normal subjects from the community, who are biologically not related to antisocial personality disorder group.

\section{Inclusion criteria for antisocial personality disorder group}

1. Male participants admitted in forensic ward.

2. Age - more than or equal to 18 years.

3. Education $-10^{\text {th }}$ standard or those who are able to read English/ Hindi.

4. Participants diagnosed with antisocial / dissocial personality disorder as per International classification of diseases-10 criteria.

5. Participants who are willing to give written informed consent.

\section{Inclusion criteria for normal group}

1. Male participants not accused for any crime.

2. Age- more than or equal to 18 years.

3. Education- $10^{\text {th }}$ standard or those who are able to read English / Hindi.

4. Participants who are willing to give written informed consent.

\section{Exclusion criteria for both the groups}

1. Participants scored more than or equal to 10 on General health questionnaire- 12 were excluded from the study. 
2. Participants with psychiatric illness and meeting any diagnostic criteria from ICD-10 were excluded

3. Participants with any physical illness were excluded.

4. Participants who are not co-operative or not able to understand the questionnaire.

\section{Sample size}

70.

\section{Study tools}

Semi structured intake pro-forma consisting of sociodemographic and crime details, International classification of diseases-10 criteria, General health questionnaire-12, Mangal emotional intelligence inventory.

\section{Methodology}

Participants willing to take part in the study were selected and written informed consent was obtained from them.

Semi-structured interview was done to gather sociodemographic details, crime details and following scales were applied i.e. Goldberg's 12 item General health questionnaire and Mangal emotional intelligence inventory. Statistical analysis was done by using SPSS (statistical package for social sciences) software v26 and significant $\mathrm{p}$ value was taken as less than 0.05 .

\section{General health questionnaire -12}

The General Health Questionnaire is a screening tool which was developed by Sir David Goldberg and Paul Williams to identify any psychiatric disorders. This instrument asks the participant if he/she has experienced any symptom or any behaviour. The instrument is considered as reliable. The 12statements are to be rated on a four-point scale with a scoring weight of 0 to 3 . Thus, the total score may range from 0 to 36. A higher score indicates increased levels of psychological distress and poor general health. ${ }^{23}$

\section{Mangal emotional intelligence inventory}

Emotional intelligence of the subjects was assessed by Dr. S. K. Mangal and Mrs. Shubhra Mangal's Mangal it has been designed for the measurement of their emotional intelligence in respect of four areas of emotional intelligence namely, intra personal awareness, inter personal awareness, intra personal management and inter personal management respectively. It has 100 items 25 each from the four areas to be answered in 'yes' or 'no'. ${ }^{24}$

\section{Result}

The study was conducted on a total sample of 70 individuals, with two groups of 35 individuals each. Participants of one group were taken from forensic ward who were accused for different kinds of crimes like thefts, robbery, rape, domestic violence, kidnapping, sex trafficking etc. and diagnosed with antisocial personality disorder as per ICD-10 and the other group had participants who were biologically not related to the first group and were selected from the community after age and gender matching.

\section{Sociodemographic variables}

(Table 1) like age, education, domicile, socio-economic status, occupation, marital status have revealed the following data. This data suggests that most of the offenders from antisocial group were unemployed whereas individuals of normal group were involved in semiskilled and skilled work. This variable (occupation) has shown statistically significant difference between the two groups $(\mathrm{p}=0.027)$. Other variables like education has revealed that most of the offenders from antisocial group had received education up to $10^{\text {th }}$ standard whereas most of the individuals from normal group had received education up to intermediate. However, this is not statistically significant $(p=0.407)$. Majority of the individuals were hailing from urban background in both the groups and belonged to low socioeconomic status. When the variable marital status was compared, it revealed that divorcees were slightly higher in offenders with antisocial personality disorder. However, this is not statistically significant $(\mathrm{p}=0.582)$. $\mathrm{p}$ value has been obtained by chi square test.

Table 1: $(*=\mathrm{p}$ value is significant $)$

\begin{tabular}{|l|c|c|c|}
\hline Socio-demographic variable & ASPD group(n=35) & Normal group(n=35) & p value \\
\hline Age (Mean \pm SD in years) & $26.028 \pm 4.348$ & $25.257 \pm 4.231$ & 0.676 \\
\hline Education & $24(68.5 \%)$ & $16(45.7 \%)$ & \\
1. $\quad 10^{\text {th }}$ standard & $11(31.5 \%)$ & $17(48.5 \%)$ & 0.407 \\
2. Intermediate & - & $2(5.7 \%)$ & \\
3. Degree & $11(31.4 \%)$ & $3(8.5 \%)$ & $0.027^{*}$ \\
\hline Occupation & $16(45.7 \%)$ & $17(48.5 \%)$ & \\
1. Unemployed & $8(22.8 \%)$ & $15(42.8 \%)$ & 0.286 \\
2. Semiskilled & - & - & \\
3. Skilled & & $5(14.2 \%)$ & \\
4. Professional & $6(17.1 \%)$ & $30((85.7 \%)$ & \\
\hline Domicile & $29(82.8 \%)$ & $15(42.8 \%)$ & \\
1. Rural & $13(37.1 \%)$ & & \\
2. Urban & Marital status & & \\
1. Single &
\end{tabular}




\begin{tabular}{|c|c|c|c|}
\hline $\begin{array}{ll}\text { 2. } & \text { Married } \\
\text { 3. } & \text { Separated } \\
\text { 4. } & \text { Divorced } \\
\end{array}$ & $\begin{array}{l}11(31.4 \%) \\
5(14.2 \%) \\
6(17.1 \%) \\
\end{array}$ & $\begin{array}{c}18(51.4 \%) \\
- \\
2(5.7 \%) \\
\end{array}$ & 0.582 \\
\hline $\begin{array}{cl}\text { Socio-economic status } \\
\text { 1. } & \text { LSES } \\
\text { 2. } & \text { MSES } \\
\text { 3. } & \text { USES }\end{array}$ & $\begin{array}{c}32(91.4 \%) \\
3(8.5 \%) \\
-\end{array}$ & $\begin{array}{c}25(71.4 \%) \\
10(28.5 \%) \\
-\end{array}$ & 0.265 \\
\hline
\end{tabular}

\section{Emotional intelligence score}

The four sub domains of emotional intelligence were measured i.e. intrapersonal awareness, interpersonal awareness, interpersonal management and interpersonal management. These sub domains showed lower values in offenders of antisocial group when compared with that of normal group and also the cumulative emotional intelligence score was less in offenders group. The difference was statistically significant $(p=0.000)$.

Table 2: $(*=p$ value is significant $)$

\begin{tabular}{|l|c|c|c|}
\hline Variable & ASPD group & Normal group & p value \\
\hline Intrapersonal awareness & $8.371 \pm 2.787$ & $16.542 \pm 2.84$ & $0.000^{*}$ \\
Interpersonal awareness & $8.314 \pm 2.948$ & $17.171 \pm 3.01$ & $0.000^{*}$ \\
Intrapersonal management & $8.628 \pm 3.218$ & $15.714 \pm 3.277$ & $0.000^{*}$ \\
Interpersonal management & $8.228 \pm 3.662$ & $15.371 \pm 3.263$ & $0.000^{*}$ \\
Total EI score & $33.5429 \pm 11.810$ & $63.800 \pm 11.442$ & $0.000^{*}$ \\
\hline
\end{tabular}

Relationship between total emotional intelligence score and number of crimes

The results have also shown significant relationship between total emotional intelligence score in antisocial personality disorder and number of crimes committed $(\mathrm{p}=0.026)$ and Pearson correlation had showed a negative value, from this it can be assumed that criminals who committed more crimes had lower emotional intelligence. (Table 3 ).

Table 3:

\begin{tabular}{|l|l|c|c|}
\hline \multicolumn{2}{|c|}{} & Total EI score & No. of crimes \\
\hline \multirow{3}{*}{ Total EI score } & Pearson Correlation & 1 & $-.377^{*}$ \\
\cline { 2 - 4 } & Sig. (2-tailed) & & .026 \\
\cline { 2 - 4 } & $\mathrm{N}$ & 35 & 35 \\
\hline \multirow{3}{*}{ No. of crimes } & Pearson Correlation & $-.377^{*}$ & 1 \\
\cline { 2 - 4 } & Sig. (2-tailed) & .026 & 35 \\
\cline { 2 - 4 } & $\mathrm{N}$ & 35 & \\
\hline \multirow{2}{*}{ *. Correlation is significant at the 0.05 level (2-tailed). }
\end{tabular}

The data obtained from criminal records show that majority of the individuals from antisocial group were undertrial prisoners and the mean of number of crimes committed was 3.514 \pm 2.345 . (Table 4 )

Table 4:

\begin{tabular}{|l|c|}
\hline Variable & Result \\
\hline Duration of stay in prison & \\
1. Less than a month & 18 \\
2. More than a month & 11 \\
3. More than a year & 6 \\
\hline Status of trial & 6 \\
1. Convicted prisoners & 28 \\
2. Under trial prisoners & 1 \\
3. Detenu prisoners & $3.514 \pm 2.345$ \\
\hline No. of crimes committed (Mean \pm SD) & \\
\hline
\end{tabular}

\section{Discussion}

1. The results obtained from the socio-demographic variables (Table 1) shows that more number of unemployed individuals were found in the offenders from antisocial group whereas normal group had semi- skilled and skilled workers. Therefore it can be inferred that there was an impairment in occupational and social functioning among the offenders with antisocial personality disorder. Other variables did not show 
statistically significant difference between both the groups.

2. In a study conducted by Nicholas Harrod et $\mathrm{al}^{11}$ on exploration of emotional intelligence levels with demographic variables has also stated that there are no significant differences between EI scores and age, domicile and household income. Significant differences were found based upon EI scores for parents education i.e., adolescents with more educated parents showed higher levels of EI score. However, this was variable was not considered in the present study. So it can be inferred that only occupation was one variable which showed significant difference in this study and others variables did not show significant difference which was supported by previous studies.

3. From the results obtained it can be said that criminals with antisocial personality disorder had lower emotional intelligence that is a mean score of $33.5 \pm 1.8$ was recorded and this falls in the category of "Poor EI" whereas the normal population had higher score with a mean value of $63.8 \pm 11.4$ which falls in the category of "Good EI". The mean emotional intelligence score of both the groups was compared and the result was statistically significant with a $p$ value of 0.000 . In other studies which were conducted in criminals by Ahmed $\mathrm{M}$ megreya, ${ }^{15}$ to assess emotional intelligence has shown that emotional intelligence was low in offenders when compared to non-offenders. In addition, emotional intelligence varied with type of offenses and this study done stated that general criminal thinking, criminal thinking styles negatively correlated with emotional intelligence. But a study conducted by Rebecca L Fix et $\mathrm{al}^{21}$ had showed that individuals with higher psychopathy had only lower intrapersonal understanding of their emotions. There are many studies which supports the finding that offenders had low levels of emotional intelligence. When compared to the study by Neelu Sharma et $\mathrm{al}^{22}$ which was conducted in criminals and normal population showed results in which criminals scored less on all the subdomains of emotional intelligence inventory when compared to the normal group. However, the aggregate score of emotional intelligence was $62 \pm 10$ which was also less than normal group which was $74.07 \pm 8.44$ but mean EI score of both the groups fall in the category of "Good EI". This study was done on criminals from a prison and personality traits of these criminals were not studied which could be one of the reason why the emotional intelligence score was good. However, criminals had scored less than normal population.

Therefore it can be implicated that offenders with antisocial personality disorder have poor control over their emotions since they have low scores on intrapersonal awareness domain and they cannot appreciate others emotions as well due to low scores on interpersonal domain.

As the offenders of antisocial group has also scored less on intrapersonal and interpersonal management it can be considered that because of these low scores there can be poor management of own emotions and also others emotions are poorly understood and managed resulting in aggression towards other's.

Impulsivity, problem solving and social skills were some of the important domains of emotional intelligence test, which is impaired in antisocial group which explains the higher rates of impulsivity and also poor problem solving and poor social skills which can further add up to greater aggression.

4. The results have also shown significant relationship between total emotional intelligence score in antisocial personality disorder and number of crimes committed $(p=0.026)$ and Pearson correlation had showed a negative value, from this it can be assumed that criminals who committed more crimes had lower emotional intelligence. (Table 3) In a study conducted by Antonietta Curci et al to determine the role of emotional intelligence and predicting criminal behaviour has stated that coping style, aggressiveness, psychopathy, and ability emotional intelligence scores have a complex pattern of interrelationship and suggested that emotional intelligence is an important feature for implementing prevention programs of criminal behaviour. ${ }^{25}$

5. All the individuals from antisocial group were using different kinds of substances and the most common substances were alcohol and nicotine. A study conducted on alcohol dependent individuals by Prakash $\mathrm{O}$ et al in 2015, showed that they had low emotional intelligence and more personality disorders.

\section{Conclusion}

The offenders with antisocial personality had significantly lower Emotional intelligence (about all domains) in comparison to the normal group so there is difficulty in dealing with emotions which can affect the number of crimes being committed. Inverse relationship was obtained between number of crimes and emotional intelligence.

\section{Strength of the Study}

There are studies done on emotional intelligence in general population and few studies done on criminals but no studies done on antisocial personality disorder group. Therefore present study was done on antisocial personality disorder group.

\section{Limitations}

1. Smaller sample size was a drawback.

2. No females included in the study thus it cannot be generalised.

\section{Implications}

The offenders with antisocial personality disorder had less emotional intelligence when compared to the normal group which could be implied as one of the reasons for committing more crimes which was also supported by this study. As 
there was an inverse relationship between emotional intelligence and number of crimes. Emotional intelligence enhancement programs can be done to improve the emotional intelligence among the prisoners. So that it will improve their quality of life and might also decrease the future crimes.

\section{Source of Funding}

None.

\section{Conflicts of Interest}

None.

\section{Acknowledgments}

Thanks to participants from Forensic ward and normal community.

\section{References}

1. Mayer JD, Salovey P. What is emotional intelligence. Emotional development and emotional intelligence: Educational implications. 1997;3:31.

2. Malterer MB, Glass SJ, Newman JP. Psychopathy and trait emotional intelligence. Pers Individ Dif. 2008;44(3):735-45.

3. Margaret HJ, Reilly GO. Psychiatric disorder, IQ, and emotional intelligence among adolescent detainees: A comparative study. Legal Criminological Psychol. 2013;18(1):30-47.

4. Megreya AM. Criminal thinking styles and emotional intelligence in Egyptian offenders. Criminal Behav Ment Health. 2013;23(1):56-71.

5. García-Sancho E, Salguero JM, Fernández-Berrocal P. Relationship between emotional intelligence and aggression: A systematic review. Aggression Violent Behav. 2014;19(5):58491.

6. Henley M, Long NJ. Teaching emotional intelligence to impulsive-aggressive youth. Reclaiming Children Youth 1999;7(4):224

7. Pizarro DA, Salovey P. Being and becoming a good person: The role of emotional intelligence in moral development and behavior. In Improving Academic Achievement 2002;247-66.

8. Meloy JR, Yakeley J. Antisocial personality disorder. In G. O. Gabbard (Ed.), Gabbard's treatments of psychiatric. American Psychiatric Publishing, Inc. 2014;1015-34.

9. Goleman D. Emotional Intelligence. New York: Bantam Books.

10. Goleman D. Working with emotional intelligence. New York: Bantam Books.

11. Harrod NR, Scheer SD. An exploration of adolescent emotional intelligence in relation to demographic characteristics. Adolescence. 2005;40(159):503.
12. Sundararajan S, Gopichandran V. Emotional intelligence among medical students: a mixed methods study from Chennai, India. BMC Med Educ. 2018;18(1):97.

13. Ravikumar R, Rajoura OP, Sharma R, Bhatia MS. A study of emotional intelligence among postgraduate medical students in Delhi. Cureus. 2017;9(1):e989.

14. Prezerakos PE. Nurse managers' emotional intelligence and effective leadership: A review of the current evidence. Open Nurs J. 2018;12:86.

15. Megreya AM. Emotional intelligence and criminal behavior. $J$ Forensic Sci. 2015;60(1):84-8.

16. Margaret HJ, Reilly GO. Psychiatric disorder, IQ, and emotional intelligence among adolescent detainees: A comparative study. Legal Criminological Psychol. 2013;18(1):30-47.

17. Qualter P, Ireland JL, Gardner KJ. Exploratory and confirmatory factor analysis of the Schutte Self-Report Emotional Intelligence Scale (SSREI) in a sample of male offenders. J Forensic Pract. 2010;12(2):43.

18. McMurran M, McGuire J, editors. Social problem solving and offending: Evidence, evaluation and evolution. John Wiley \& Sons; 2005.

19. Kirsch LG, Becker JV. Emotional deficits in psychopathy and sexual sadism: Implications for violent and sadistic behavior. Clin Psychol Rev. 2007;27(8):904-22.

20. Bergeron TK, Valliant PM. Executive function and personality in adolescent and adult offenders vs. non-offenders. J Offender Rehabil. 2001;33(3):27-45.

21. Fix RL, Fix ST. Trait psychopathy, emotional intelligence, and criminal thinking: Predicting illegal behavior among college students. Int J Law Psychiatry. 2015;42:183-8.

22. Sharma N, Prakash O, Sengar KS, Chaudhury S, Singh AR The relation between emotional intelligence and criminal behavior: A study among convicted criminals. Ind Psychiatry J. 2015;24(1):54.

23. Goldberg DP. The detection of psychiatric illness by questionnaire. Maudsley monograph. 1972;21.

24. Mangal SK, Mangal S. Manual for mangal emotional intelligence inventory. Agra: National Psychological Corporation; 1985.

25. Curci A, Cabras C, Lanciano T, Soleti E, Raccis C. What is over and above psychopathy? The role of ability emotional intelligence in predicting criminal behavior. Psychiatry, Psychol Law. 2017;24(1):139-51.

How to cite this article: Agnihotri S, Rayirala A. A comparative study of emotional intelligence in offenders with antisocial personality disorder and normal population at a tertiary care centre in Hyderabad, Telangana. Telangana $J$ Psychiatry. 2020;6(2):113-118. 